\title{
ASK1 facilitates tumor metastasis through phosphorylation of an ADP receptor $\mathrm{P}^{2} \mathrm{Y}_{12}$ in platelets
}

\author{
Miki Kamiyama ${ }^{1}$, Toshiaki Shirai ${ }^{2}$, Shogo Tamura, ${ }^{2,6}$ Katsue Suzuki-Inoue ${ }^{2}$, Shogo Ehata ${ }^{3}$, Kei Takahashi ${ }^{3}$, Kohei Miyazono $^{3}$, \\ Yoshihiro Hayakawa ${ }^{4}$, Takehiro Sato ${ }^{1}$, Kohsuke Takeda ${ }^{5}$, Isao Naguro ${ }^{1}$ and Hidenori Ichijo ${ }^{\star, 1}$
}

Tumor metastasis is the major cause of deaths in cancer patients and is modulated by intertwined stress-responsive signaling cascades. Here we demonstrate that deletion of stress-responsive apoptosis signal-regulating kinase 1 (Ask1) in platelets results in unstable hemostasis and drastic attenuation of tumor lung metastasis, both of which are attributable to platelet dysfunction. Platelet-specific deletion of Ask1 in mice leads to defects in ADP-dependent platelet aggregation, unstable hemostasis and subsequent attenuation of tumor metastasis. We also revealed that activating phosphorylation of Akt is attenuated in Ask1deficient platelets, contrary to the previous reports suggesting that Akt is negatively regulated by ASK1. Mechanistically, ASK1$\mathrm{JNK} / \mathrm{p} 38$ axis phosphorylates an ADP receptor $\mathrm{P}^{2} \mathrm{Y}_{12}$ at Thr345, which is required for the ADP-dependent sustained Akt activity that is vital to normal platelet functions. Our findings offer insight into positive regulation of Akt signaling through $\mathrm{P}_{2} \mathrm{Y}_{12}$ phosphorylation as well as MAPK signaling in platelets by ASK1 and suggest that ASK1-JNK/p38 axis provides a new therapeutic opportunity for tumor metastasis.

Cell Death and Differentiation (2017) 24, 2066-2076; doi:10.1038/cdd.2017.114; published online 28 July 2017

Tumor metastasis is the spread of tumor cells from primary tumors to other distant tissues and/or organs and is fatal to cancer patients. Metastatic seeding is a highly inefficient process, thus hindering the investigation of its precise molecular mechanism. ${ }^{1}$ A plethora of evidence suggests that stress-responsive signaling cascades play pivotal roles in the host microenvironment. ${ }^{1}$ Mitogen-activated protein kinase (MAPK) pathways are the representative stress-responsive cascades that exert proper cellular responses to divergent environmental stimuli. In response to various stressors, upstream MAPK kinase kinase (MAP3K) phosphorylates and activates MAPK kinase (MAP2K), and MAP2K subsequently activates MAPK. Activated MAPK regulates and induces a wide range of physiological responses. ${ }^{2,3}$ Although MAPKs such as c-Jun NH2-terminal kinase (JNK) and p38 have been revealed to play multifaceted roles in the host environment during tumor progression including tumor metastasis, ${ }^{4}$ the upstream regulatory mechanism of these kinases in the context of tumor metastasis was totally unknown. ASK1 is a stress-responsive Ser/Thr MAP3K in the JNK and $p 38$ pathways ${ }^{5,6}$ and accumulating evidence indicates that ASK1 plays important roles in tumorigenesis by regulating apoptosis and inflammation; ${ }^{7,8}$ however, little is known about ASK1's roles in tumor metastasis.

Platelets are anuclear, small cell fragments released from megakaryocytes. Platelets surround tumor cells by adhesion and aggregation in the bloodstream and support tumor metastasis by protecting tumor cells from cell death and immunosurveillance, facilitating their interaction with tumorpromoting leukocytes and assisting their adhesion to vascular endothelial cells. ${ }^{9}$ The tumor-promoting effects of platelets have been investigated by gene ablation of relevant molecules such as P-selectin ${ }^{10}$ and P2Y 12 (ref. 11) in mice, little reports have referred to the mechanistic insights of these molecules in tumor metastasis.

In this study, we elucidated the impact of ASK1 in the host environment on tumor metastasis and the detailed molecular mechanism of its involvement through regulation of downstream JNK and p38 in platelet functions. Namely, we revealed the regulatory mechanism of $\mathrm{P}_{2} \mathrm{Y}_{12}$ by ASK1-JNK/p38 axis through phosphorylation, thereby linking $G$ protein-coupled receptor (GPCR)-mediated ADP signaling and MAPK pathways in platelets.

\section{Results}

Ask1 deficiency in the host environment attenuates tumor lung metastasis. To directly analyze the potential involvement of ASK1 in tumor metastasis, we utilized the experimental lung metastasis model established by intravenous (i.v.) injection of B16F10 melanoma and Lewis lung carcinoma cells constitutively expressing luciferase (B16F10luc-G5 and 3LL-Luc2 cells, respectively). Fourteen days after i.v. injection of tumor cells, we observed a dramatically

\footnotetext{
${ }^{1}$ Laboratory of Cell Signaling, Graduate School of Pharmaceutical Sciences, The University of Tokyo, 7-3-1 Hongo, Bunkyo-ku, Tokyo 113-0033, Japan; ${ }^{2}$ Department of Clinical and Laboratory Medicine, Faculty of Medicine, University of Yamanashi, 1110 Shimokato, Chuo, Yamanashi 409-3898, Japan; ${ }^{3}$ Department of Molecular Pathology, Graduate School of Medicine, The University of Tokyo, 7-3-1 Hongo, Bunkyo-ku, Tokyo 113-0033, Japan; ${ }^{4}$ Division of Pathogenic Biochemistry, Institute of Natural Medicine, University of Toyama, 2630 Suginoki, Toyama 930-0194, Japan and ${ }^{5}$ Division of Cell Regulation, Graduate School of Biomedical Sciences, Nagasaki University, 1-14 Bunkyo-machi, Nagasaki 852-8521, Japan

*Corresponding author: H Ichijo, Laboratory of Cell Signaling, Graduate School of Pharmaceutical Sciences, The University of Tokyo, 7-3-1 Hongo, Bunkyo-ku, Tokyo 113-0033, Japan. Tel: +81 35841 4858; E-mail: ichijo@mol.f.u-tokyo.ac.jp

${ }^{6}$ Current address: S Tamura, Department of Pathophysiological Laboratory Sciences, Nagoya University Graduate School of Medicine, Nagoya, Japan.

Received 11.4.17; revised 29.5.17; accepted 08.6.17; Edited by G Melino; published online 28.7.17
} 
reduced number of tumor nodules in the lungs. Consistent with the result, the luciferase activity of the lung lysates of Ask $1^{-1-}$ mice was significantly reduced compared with control wild-type $(W t)$ mice (Figures $1 \mathrm{a}$ and b). We also utilized an in vivo bioluminescence imaging to monitor the temporal fate of tumor cells i.v. injected. The signal of 3LLLuc2 cells was visible in lungs of Wt mice from day 14 after i.v. injection and increased with time (Figures 1c and d). However, consistent with our macroscopic observations, the signal intensity in the lungs was significantly low in $A s k 1^{-1-}$ mice even at day 26 after injection (Figure 1c). Moreover, the survival rate of $A s k 1^{-1-}$ mice was dramatically increased after i.v. injection of 3LL-Luc2 cells (Figure 1e).

Tumor metastasis consists of multiple steps. Tumor cells that successfully invade from primary lesions are transported to secondary metastatic sites (dissemination process), form emboli within the vasculature and adhere to endothelial cells (colonization process). Only a small fraction of surviving tumor cells can extravasate and form micrometastases, which gradually become macroscopic metastases by tumor cell proliferation. ${ }^{12}$ The experimental lung metastasis model can recapitulate the sequential steps including dissemination, colonization, extravasation, proliferation and eventually formation of macroscopic metastasis. We next measured the time-dependent changes of luciferase activity of the lung lysates from $1 \mathrm{~h}$ up to 7 days after injection. The luciferase activity dramatically decreased over time until around $24 \mathrm{~h}$ after injection and thereafter it starts to increase exponentially in Wt mice (Figure 1f), reflecting the colonization process followed by proliferation of tumor cells in the course of metastasis. There was minor difference in the dissemination process at $1 \mathrm{~h}$ after injection between $W t$ and $A s k 1^{-1-}$ mice, whereas $A s k 1^{-1-}$ mice showed dramatic attenuation in luciferase activity of the lung lysates as early as 3 days after injection (Figure 1f), suggesting that ASK1 is involved in the colonization and/or proliferation process (within 3 days after injection) of tumor metastasis.

To examine the potential involvement of ASK1 in tumor cell proliferation during the formation of macroscopic metastases after extravasation, lung carcinoma-derived 3LL-Luc2 cells were orthotopically injected into the lung (Supplementary Figure S1a). There was no significant difference, however, in tumor cell growth between Wt and $A s k 1^{-1-}$ mice. We also observed no difference in the ectopic growth of 3LL-Luc2 cells subcutaneously injected into the dorsal skin of $W t$ and Ask $1^{-1-}$ mice (Supplementary Figure S1b). Thus, we hypothesized that Ask1 deficiency may affect the colonization stage rather than the proliferation stage after formation of micrometastases.

ASK1 in bone marrow-derived cells facilitates tumor lung metastasis. We next generated bone marrow chimeric mice to identify the cell types in which ASK1 regulates tumor metastasis. The luciferase activity in the lungs was reduced in Wt mice whose bone marrow was replaced with $A s k 1^{-1-}$ mice (Ask $1^{-1-}$-Wt mice) as well as in $A s k 1^{-1-}$ mice whose bone marrow was replaced with Wt mice (Wt-Ask $1^{-1-}$ mice) compared with the control (Wt-Wt) mice (Figure 2a). These results suggest that ASK1 contributes to metastasis in both bone marrow-derived cells and recipient cells. Among bone marrow-derived cells, critical roles of myeloblasts such as granulocytes, monocytes and macrophages in tumor metastasis have been suggested. ${ }^{13}$ Hence, we utilized myeloblastspecific Ask1-deficient mice (Lysm-cre; Ask1 $1^{F / F}$ mice). Lysmcre; $A s k 1^{F / F}$ mice exhibited almost complete deletion of Ask1 in peritoneal macrophages (Figure $2 b$ ) but not in platelets (Figure $2 \mathrm{c})^{14}$ or whole lungs (Figure $2 \mathrm{~d}$ ). Surprisingly, the luciferase activities of the lung lysates from $L y s m$-Cre; Ask $1^{F / F}$ mice and $A s k 1^{F / F}$ mice were comparable at 14 days after injection of B16F10-luc-G5 cells (Figure 2e) and 3LL-Luc2 cells (Figure 2f), suggesting that ASK1 in bone marrowderived cells other than myeloblasts regulates tumor lung metastasis.

Platelet-intrinsic Ask1 deficiency leads to unstable hemostasis. Platelets are non-myeloblastic bone marrowderived cells and play critical roles in hematogenous tumor metastasis. The tumor metastasis-promoting effects of platelets are inhibited by the decline in number or function. ${ }^{9}$ It was recently reported that ASK1 maintains hemostasis through platelet granule secretion by using conventional Ask $1^{-1-}$ mice. ${ }^{15}$ Similar to the report, $A s k 1^{-1-}$ mice showed no differences in the number of platelets and hematological parameters compared with Wt mice (Supplementary Table S1) as well as surface expression of major platelet receptors (Supplementary Figure S2a). In addition, the bleeding time in tail bleeding assays (Supplementary Figure S2b) and the occlusion time in $\mathrm{FeCl}_{3}$-induced thrombosis assays (Supplementary Figure S2c) were also confirmed to be significantly prolonged in $\mathrm{ASK}^{-1-}$ mice. However, these phenotypes of Ask $1^{-1-}$ mice in hemostasis cannot exclude the potential involvement of other cell types (such as endothelial cells) than platelets in hemostasis. To examine if Ask 1 deficiency in platelets contributes to unstable hemostasis, we newly generated platelet-specific Ask1-deficient mice (Pf4-cre; Ask $1^{F / F}$ mice). ${ }^{16}$ Pf4-cre; Ask $1^{F / F}$ mice exhibited almost complete deletion of ASK1 in platelets (Figure 3a) but not in whole lungs (Figure $3 b$ ). The hematological parameters and surface expression of major platelet receptors of Pf4-cre; Ask $1^{F / F}$ mice were indistinguishable from Ask $1^{\mathrm{F} / \mathrm{F}}$ mice (Supplementary Table S1 and Supplementary Figure S3). Moreover, both the bleeding time in tail bleeding assays (Figure $3 \mathrm{c}$ ) and the occlusion time in $\mathrm{FeCl}_{3}$-induced thrombosis assays (Figure $3 \mathrm{~d}$ ) were significantly prolonged in Pf4-cre; Ask $1^{F / F}$ mice. These data strongly suggest that platelet-intrinsic ASK1 is critical to unstable hemostasis phenotype observed in conventional $A s k 1^{-1-}$ mice.

Activating phoshorylation of Akt, JNK and p38 is reduced in Ask1-deficient platelets. JNK and p38 are downstream effectors of ASK $1 .{ }^{5,6}$ Also, they are known to have critical roles in hemostasis and thrombosis: ${ }^{17,18}$ hence, we speculated that ASK1 functions as an upstream regulator of JNK and p38 in platelets. As expected, in platelets of $A s k 1^{-1-}$ and Pf4-cre; Ask $1^{F / F}$ mice, the activating phosphorylation of JNK and p38 were dramatically attenuated (Figures $3 e$ and f). Interestingly, the activating phosphorylation of Akt (at Thr308 and Ser473), which is required for platelet aggregation and hemostasis, ${ }^{19}$ was strongly reduced in platelets of $A s k 1^{-1-}$ and Pf4-cre; Ask $1^{F / F}$ mice (Figures $3 e$ and f). ASK1 and Akt were reported 
a
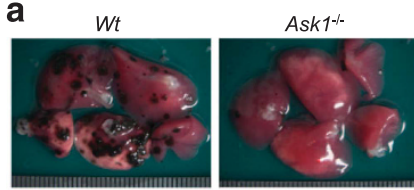

B16F10-luc-G5 metastasis
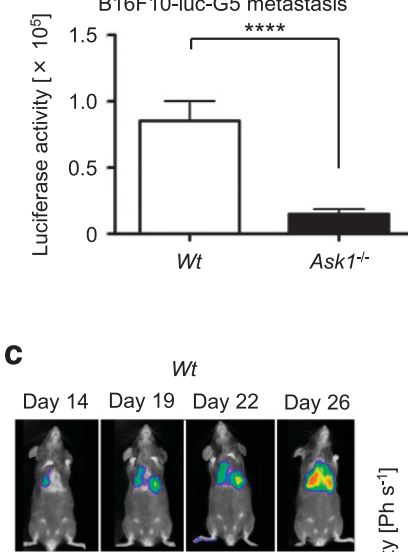

Ask $1^{1-1}$

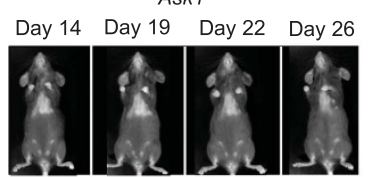

e

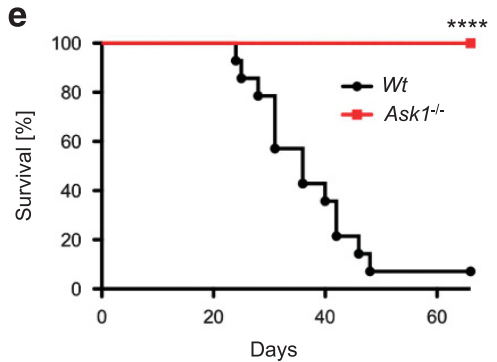

b
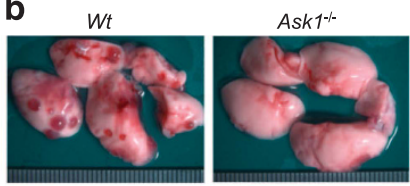

3LL-Luc2 metastasis

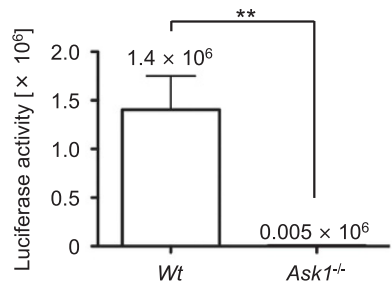

d

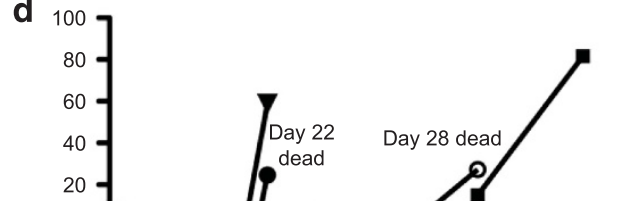

- $W t-1$ (died on day 28)

$\rightarrow W t-2$ (died on day 29)

\pm Wt-3

$\rightarrow W t-4$ (died on day 21)

$\rightarrow W t-5$ (died on day 22)

$\rightarrow W t-6$ (died on day 22)

- Ask $1^{-1-}-1$

- Ask $1^{1 /-}-2$

$\rightarrow$ Ask $1^{-1-}-3$

$\prec$ Ask ${ }^{-1-4}$

- Ask 1--5

- Ask $^{-1-6}$

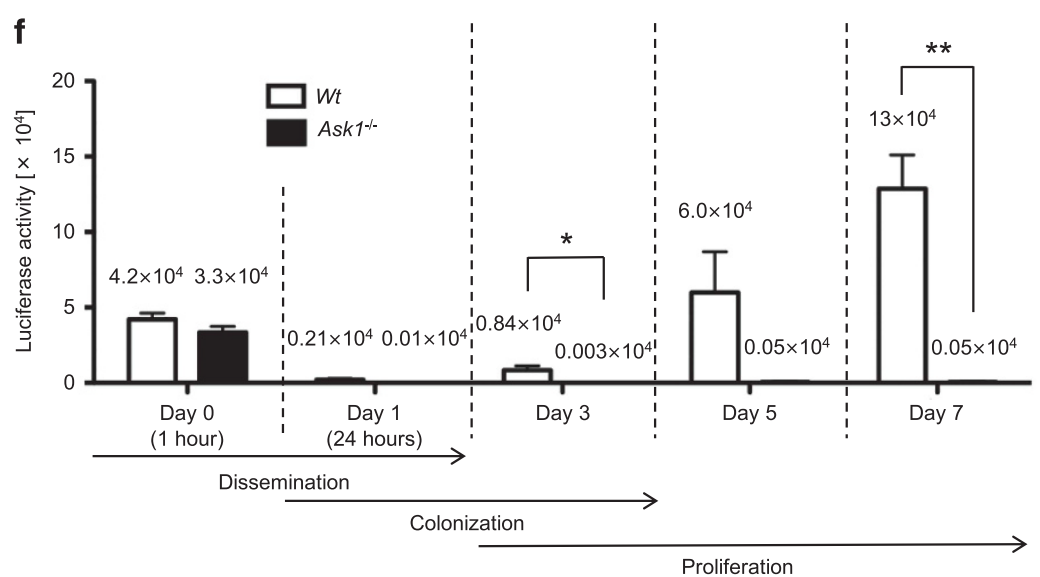

Figure 1 Ask1 deficiency in mice attenuates tumor lung metastasis. ( $\mathbf{a}$ and $\mathbf{b}$ ) Macroscopic views of metastatic foci in lungs (upper panels) and luciferase activity of lung lysates (lower panels) analyzed 14 days after i.v. injection of B16F10-luc-G5 cells (a) and 3LL-Luc2 cells (b). (a) Wt mice: $n=24$, Ask $1^{1-}$ mice: $n=23$. (b) Wt mice: $n=4$, Ask $1^{-1}$ mice: $n=4$. (c) Mice i.v. injected with 3LL-Luc2 cells were analyzed using an in vivo bioluminescence imaging. (d) Luciferase signal intensity from $3 \mathrm{LL}-L u c 2$ cells in the lungs was measured over time using an in vivo bioluminescence imaging (Wtmice: $n=6, A s k 1^{-1}$ mice: $n=6$ ). Unless otherwise indicated, the mice survived until the end of the experiment (day 29). (e) The survival of mice i.v. injected with 3LL-Luc2 cells was monitored (Wt mice: $n=14$, Ask $1^{-1-}$ mice: $n=15$ ). (f) Luciferase activity of the lung lysates at indicated time points after tail vein injection of 3 LL-Luc2 cells $\left(n=3\right.$ per group). The data are shown as the mean \pm s.e.m. ${ }^{* * *} P<0.0001 ;{ }^{* *} P<0.01 ;{ }^{*} P<0.05$. Unpaired Student's $t$-tests (a, b and f) and Gehan-Breslow-Wilcoxon test (e) 
a
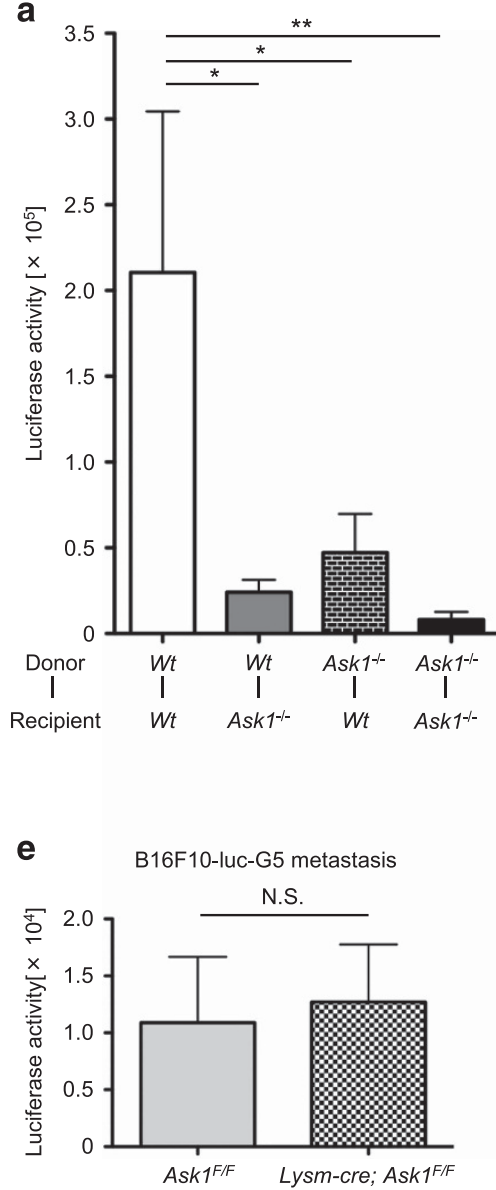

b
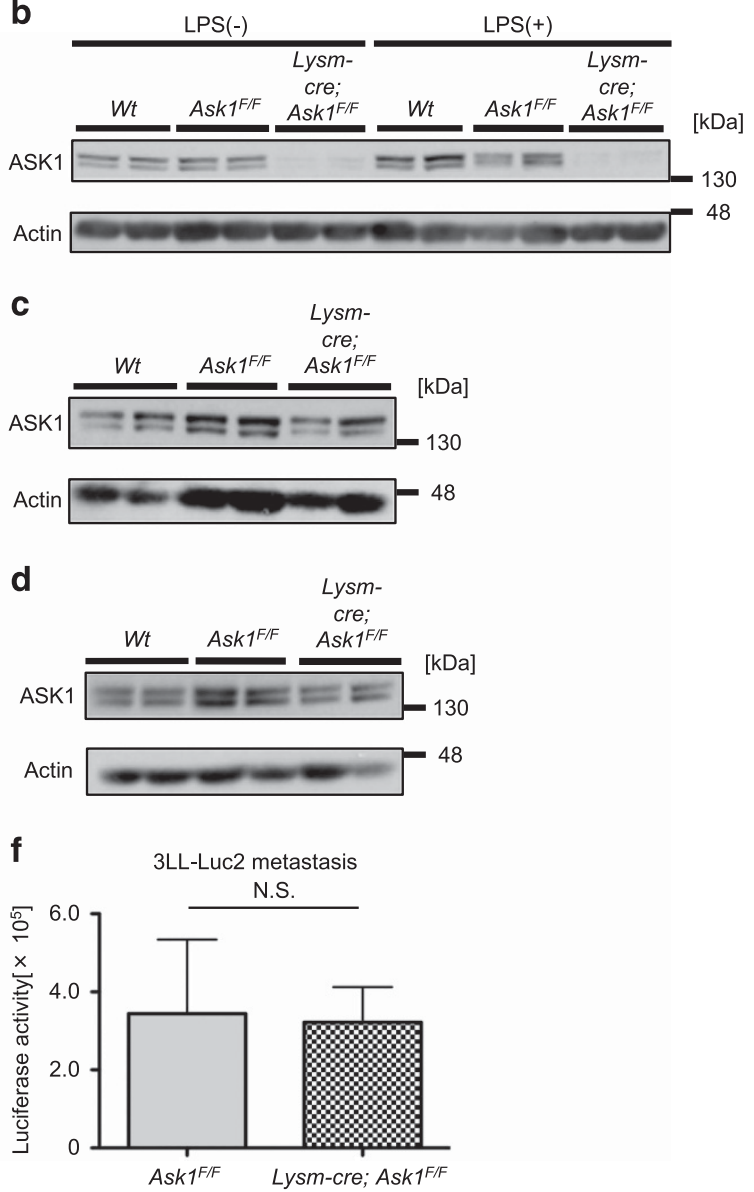

Figure 2 Ask1 deficiency in multiple cell types other than myeloblasts attenuates tumor lung metastasis. (a) Luciferase activity of lung lysates of bone marrow chimeric mice 7 days after i.v. injection of 3LL-Luc2 cells (Wt-Wt mice: $n=14$, Wt-Ask1 $1^{-1-}$ mice: $n=12$, Ask $1^{-1-}$-Wt mice: $n=14$, Ask $1^{-1-}$-Ask $1^{-1-}$ mice: $n=16$ ). (b-d) Western blot of peritoneal macrophages (b), platelets (c) and lungs (d) of Wt, Ask1 $1^{\mathrm{F} / F}$ and $L y s m-c r e ; A s k 1^{\mathrm{F} / F}$ mice $(n=2$ each). (e and f) Luciferase activity of lung lysates 14 days after i.v. injection of B16F10-luc-G5 cells (e) and 3LL-Luc2 cells (f). (e) Ask $1^{\mathrm{F} / F}$ mice: $n=7$, Lysm-cre; Ask1 ${ }^{\mathrm{F} / F}$ mice: $n=8$, (f) Ask $1^{\mathrm{F} / F}$ mice: $n=10$, Lysm-cre; Ask $1^{\mathrm{F} / F}$ mice: $n=14$. The data are shown as the mean \pm s.e.m. ${ }^{* \star} P<0.01 ;{ }^{*} P<0.05$; NS, nonsignificant. One-way ANOVA followed by Ryan's method (a) and unpaired Student's $t$-tests (e and $\mathbf{f})$

to mutually inhibit their activities by phosphorylation. ${ }^{20,21}$ Thus, our data contrast to the previous reports in that ASK1 positively, rather than negatively, regulates Akt activity, suggesting the distinctive regulatory mechanism of Akt phosphorylation by ASK1 in platelets. In sum, these results suggest that ASK1 may be involved in normal platelet functions through activations of JNK, p38 and Akt.

Ask1-deficient platelets are refractory to ADP-dependent stimulations. To investigate what kind of signals ASK1 regulates in the context of platelet aggregation, we next studied in vitro platelet aggregation induced by various agonists. When platelets of $A s k 1^{-1-}$ mice were exposed to collagen, PAR-4 activating peptide and rhodocytin, the ligand of CLEC-2, platelet aggregation was significantly reduced compared with Wt mice (Supplementary Figures S4a-c). ${ }^{15}$ By contrast, thrombin-induced platelet aggregation was not abrogated in $A s k 1^{-1-}$ mice (Supplementary Figure S4d). Platelet aggregation induced by collagen or rhodocytin is largely dependent on ADP as a secondary mediator. ${ }^{22-24}$
Moreover, PAR-4 activating peptide but not thrombin depends on $A D P$ receptor $P 2 Y_{12}$ to activate integrin $a$ llb $\beta 3$ and subsequent fibrinogen binding, and eventually induces platelet aggregation. ${ }^{25}$ Considering these reports, our data suggest that ASK1 contributes to ADP-dependent platelet activation. As expected, platelet aggregation induced by ADP was dramatically abrogated in $A s k 1^{-1-}$ mice (Supplementary Figure S4e). Similar to Ask $1^{-1-}$ mice, platelet aggregation of Pf4-cre; Ask $1^{F / F}$ mice was attenuated under stimulation with collagen (Figure $3 \mathrm{~g}$ ) and ADP (Figure $3 \mathrm{~h}$ ) but not with thrombin (Figure 3i). In summary, Ask1 deficiency attenuates ADP-dependent aggregation in platelets.

ASK1 regulates phosphorylation of ADP receptor, $\mathrm{P}_{2} \mathrm{Y}_{12}$. ADP activates two purinergic GPCRs, $P 2 Y_{1}$ and $P 2 Y_{12}$, to initiate platelet aggregation. $\mathrm{P}_{2} \mathrm{Y}_{1}$ and $\mathrm{P}_{2} \mathrm{Y}_{12}$ associate with $G_{q}$ and $G_{i}$, respectively, for full platelet activation. Binding of $\mathrm{ADP}$ to $\mathrm{P}_{2} \mathrm{Y}_{1}$ induces elevation of intracellular calcium and activation of Rho kinases, whereas ADP binding to $P 2 Y_{12}$ activates the PI3K-Akt pathway and inhibits adenylyl cyclase 
a

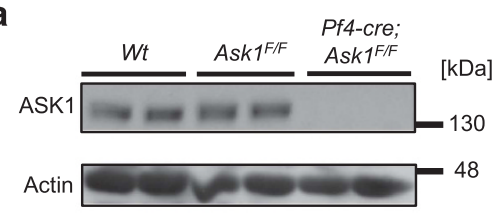

b

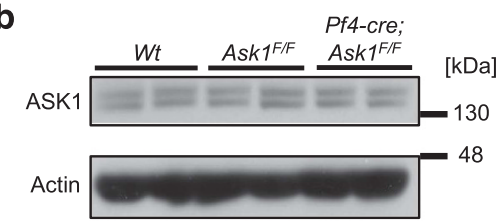

c

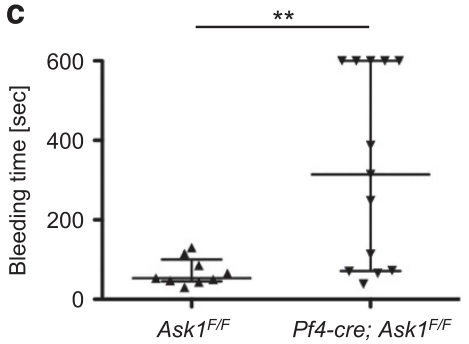

d

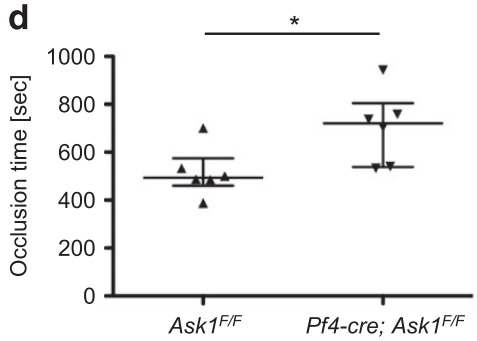

e

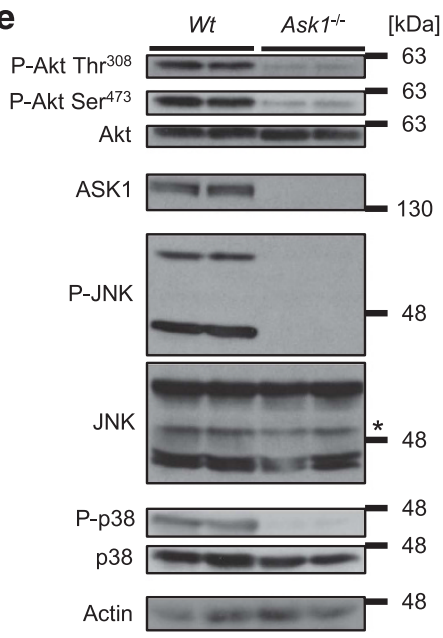

\section{g}
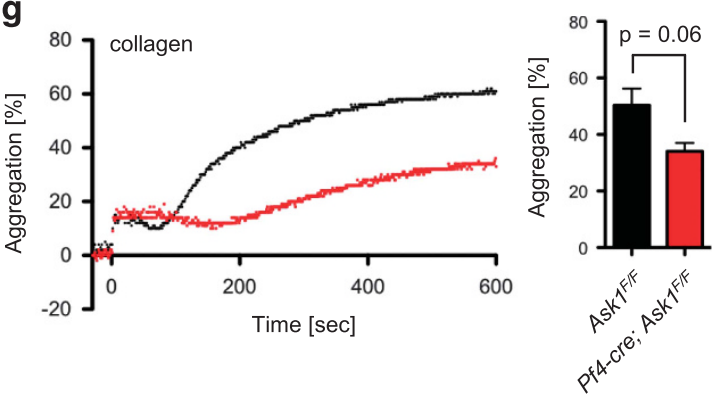

h
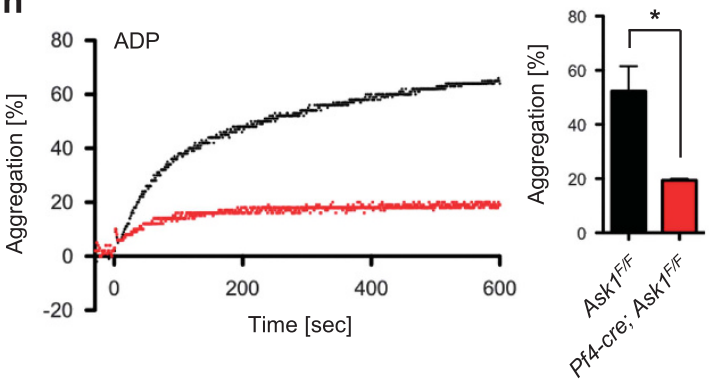

i
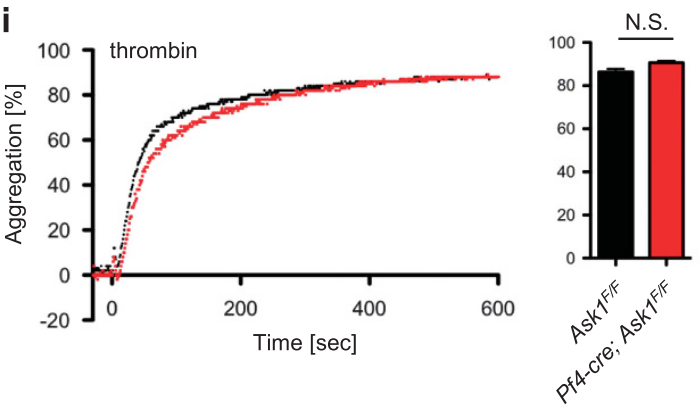

f
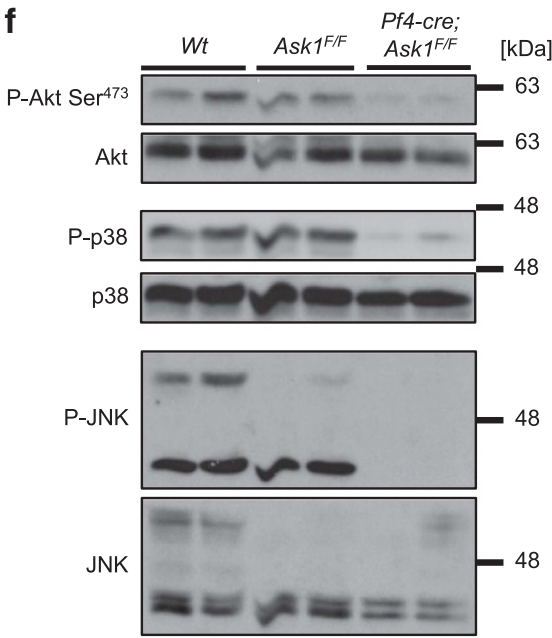

Figure 3 Platelet-specific Ask1 deletion leads to unstable hemostasis and attenuation in Akt activity. (a and $\mathbf{b})$ Western blot of platelets (a) and lungs (b) of Wt, Ask1 ${ }^{\mathrm{F} / F}$ and Pf4-cre; Ask $1^{F / F}$ mice ( $n=2$ each). (c) Bleeding time in the tail bleeding assay (Ask $1^{F / F}$ mice: $n=9$, Pf4-cre; Ask $1^{F / F}$ mice: $n=13$ ). (d) Occlusion time in the femoral artery in the $\mathrm{FeCl}_{3}$-induced thrombosis assay (Ask ${ }^{\mathrm{F} / \mathrm{F}}$ mice: $n=6$, Pf4-cre; $A s k{ }^{\mathrm{F} / \mathrm{F}}$ mice: $n=6$ ). The data are presented with the median and interquartile range. (e and $\mathrm{f}$ ) Western blot of platelets of $W t$ and $A s k 1^{-1}$ mice (e, ${ }^{*}$ non-specific band), and $W t, A s k 1^{F / F}$ and Pf4-cre; Ask $1^{F / F}$ mice (f) $\left(n=2\right.$ each). (g-i) Platelet aggregation of Ask $1^{F / F}$ and Pf4-cre; Ask $1^{F / F}$ mice induced by $1 \mu \mathrm{g} / \mathrm{ml}$ collagen (g), $10 \mu \mathrm{M}$ ADP (h) and $0.025 \mathrm{U} / \mathrm{ml}$ thrombin (i). Representative traces (left) and the maximal aggregation within 10 min of measurement (right) are presented. The data are presented as the mean \pm s.e.m. $\left(n=3\right.$ each). ${ }^{*} P<0.01 ;{ }^{*} P<0.05$; NS, non-significant. Mann-Whitney U-test (c and $\left.\mathbf{d}\right)$ and unpaired Student's t-tests $(\mathbf{g}-\mathbf{i})$ 
a

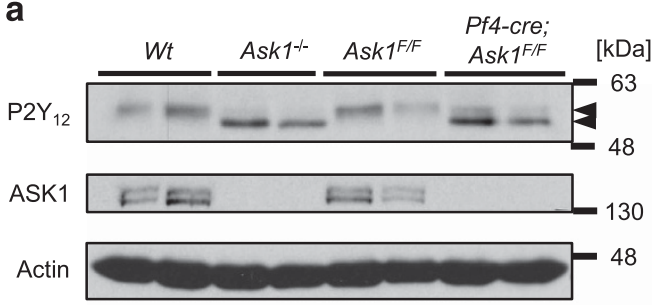

C

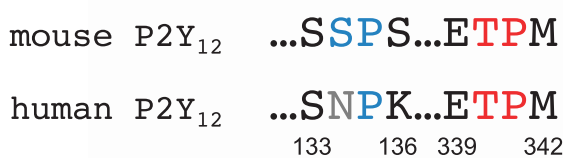

d

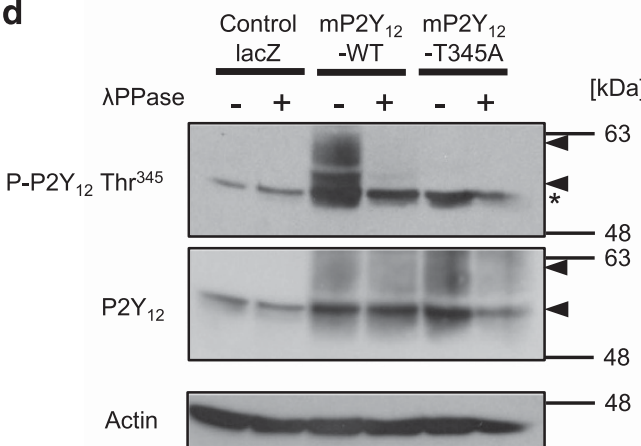

b

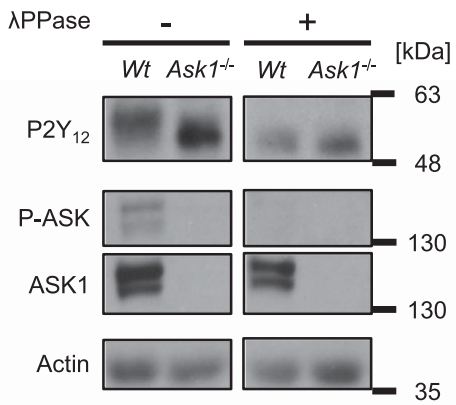

e

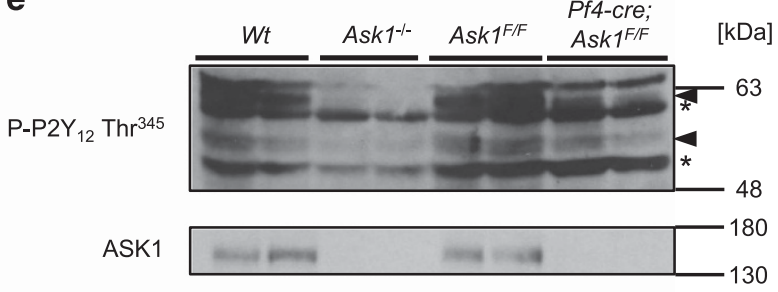

Actin

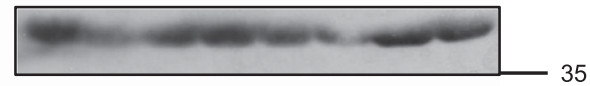

Figure 4 ASK1 regulates the phosphorylation of $\mathrm{P} 2 \mathrm{Y}_{12}$ at Thr345 in platelets. (a) $\mathrm{P} 2 \mathrm{Y}_{12}$ expression in platelets of $W t, A s k 1^{-1-}, A s k 1^{\mathrm{F} / \mathrm{F}}$ and $P f 4-c r e ; A s k 1^{\mathrm{F} / F}$ mice $(n=2$ each). (b) Platelet lysates of $W t$ and $A s k 1^{-1-}$ mice were subjected to buffer or $\lambda$ PPase to examine the impact of dephosphorylation on the bands for P2Y ${ }_{12}$. (c) Intracellular consensus phosphorylation sites for JNK and p38 ((S/T)P sites) in mouse P2Y ${ }_{12}$ were compared with those of human P2Y ${ }_{12}$. The SP site of mouse P2Y ${ }_{12}$ denoted in blue is not

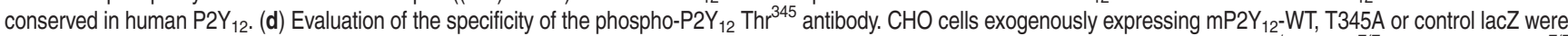
stimulated with $10 \mu \mathrm{M}$ ADP for $5 \mathrm{~min}$, lysed and subjected to dephosphorylation by $\lambda$ PPase. (e) Western blot of mouse platelets of Wt, Ask $1^{-I-}$, Ask $1^{\mathrm{F} / \mathrm{F}}$ and Pf4-cre; Ask $1^{\mathrm{F} / \mathrm{F}}$ mice $\left(n=2\right.$ each) (arrowhead; $\mathrm{P}-\mathrm{P} 2 \mathrm{Y}_{12} \mathrm{Thr}^{345}$ or $\mathrm{P}_{2} \mathrm{Y}_{12}$, ${ }^{*}$ nonspecific band)

(AC), etc. ${ }^{26}$ As mentioned above, the activating phosphorylation of Akt was attenuated in platelets of $A s k 1^{-1-}$ mice as well as of Pf4-cre; Ask $1^{\mathrm{F} / \mathrm{F}}$ mice (Figures $3 \mathrm{e}$ and $\mathrm{f}$ ). Considering that a large proportion of Akt activation by ADP is attributable to $\mathrm{P}_{2} \mathrm{Y}_{12}$ in platelets, ${ }^{27}$ we hypothesized that ASK1 may modulate ADP signaling through the $\mathrm{P}_{2} \mathrm{Y}_{12}$ receptor.

Platelet $\mathrm{P}_{2} \mathrm{Y}_{12}$ protein levels were comparable in $A s k 1^{-1-}$, Pf4-cre; Ask $1^{\mathrm{F} / F}$ and control (Wt and Ask1F/F) mice' (Figure 4a). Interestingly, however, the bands for $\mathrm{P}_{2} \mathrm{Y}_{12}$ from Ask $1^{-1-}$ and Pf4-cre; Ask $1^{F / F}$ mice migrated faster than the band from control mice in SDS-PAGE (Figure 4a). Thus, we assumed that aberrant post-translational modification of $\mathrm{P}_{2 Y_{12}}$ in Ask1-deficient platelets causes platelet dysfunction. Previous reports indicate that $\mathrm{P}_{2} \mathrm{Y}_{12}$ is subject to phosphorylation and glycosylation. ${ }^{28}$ When platelet lysates were treated with the protein phosphatase $\lambda$ PPase, the band for $\mathrm{P}_{2} \mathrm{Y}_{12}$ from platelets of Wt mice was downshifted to the same position of that from $A s k 1^{-1-}$ mice (Figure 4b), suggesting that ASK1 modulates $\mathrm{P}_{2} \mathrm{Y}_{12}$ phosphorylation.

Phosphorylation of $\mathrm{mP}_{2} \mathrm{Y}_{12}$ at Thr345 by ASK1-JNK/p38 axis sustains Akt signaling induced by ADP stimulation. Next, we attempted to identify the phosphorylation site(s) of $\mathrm{P}_{2} \mathrm{Y}_{12}$ affected by ASK1. Considering that JNK and p38 (downstream of ASK1) regulate platelet functions and hemostasis, ${ }^{17,18}$ we assumed that these kinases might be responsible for the direct phosphorylation. We searched for consensus phosphorylation sites (Ser-Pro or Thr-Pro) targeted by JNK and p38 in P2Y ${ }_{12}$. Only one Thr-Pro (TP) site at the $\mathrm{C}$-terminus was conserved between human and mouse $\mathrm{P}_{2 \mathrm{Y}_{12}}\left(\mathrm{mP}_{2} \mathrm{Y}_{12}\right.$; Figure $\left.4 \mathrm{c}\right)$. To determine if ASK1 regulates phosphorylation of this TP site in mouse platelets, we generated an anti-phospho-P2Y 12 antibody $\left(\mathrm{p}-\mathrm{P}_{2} \mathrm{Y}_{12} \mathrm{Thr}^{345}\right)$ as described in the Materials/Subjects and Methods $\left(\mathrm{Thr}^{340}\right.$ in human). The signal of the $\mathrm{p}-\mathrm{P}_{2} \mathrm{Y}_{12} \mathrm{Thr}^{345}$ antibody was specifically detected in $\mathrm{CHO}$ cells exogenously expressing $\mathrm{mP}_{2} \mathrm{Y}_{12}$-WT but not phosphorylation-defective $\mathrm{mP}_{2} \mathrm{Y}_{12^{-}}$ T345A or control lacZ, and the signal was completely abolished by $\lambda$ PPase treatment (Figure $4 d$ ). We thus investigated the phosphorylation status of endogenous P2Y 12 at Thr345 in platelets. Strikingly, Thr345 phosphorylation of $\mathrm{P}_{2} \mathrm{Y}_{12}$ was strongly attenuated in Ask1-deficient platelets, suggesting that ASK1 is responsible for this phosphorylation in platelets (Figure 4e).

We next evaluated the impact of the defects in $\mathrm{P}_{2} \mathrm{Y}_{12}$ phosphorylation on the downstream signaling. ADP-dependent activation of Akt monitored by phosphorylation of Akt at Ser473 was clearly increased when $\mathrm{CHO}$ cells exogenously 
express $\mathrm{mP}_{2} \mathrm{Y}_{12}$-WT but not control lacZ (Figure 5a), confirming that exogenously expressed $\mathrm{mP}_{2} \mathrm{Y}_{12}$ can activate Akt in response to ADP stimulation. ADP stimulation led to sustained Akt activity up to 120 min in $\mathrm{CHO}$ cells expressing $\mathrm{mP}_{2} \mathrm{Y}_{12}-\mathrm{WT}$, while it was attenuated from $60 \mathrm{~min}$ after stimulation in $\mathrm{mP}_{2} \mathrm{Y}_{12}-\mathrm{T} 345 \mathrm{~A}$ expressing cells (Figure $5 \mathrm{~b}$ ).

a

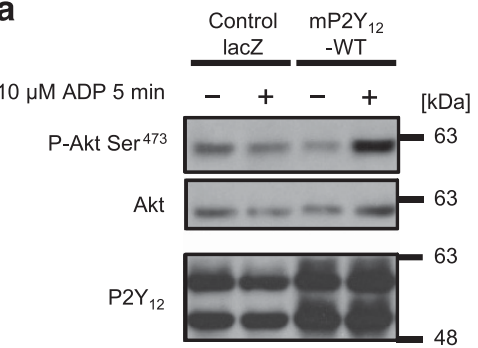

b

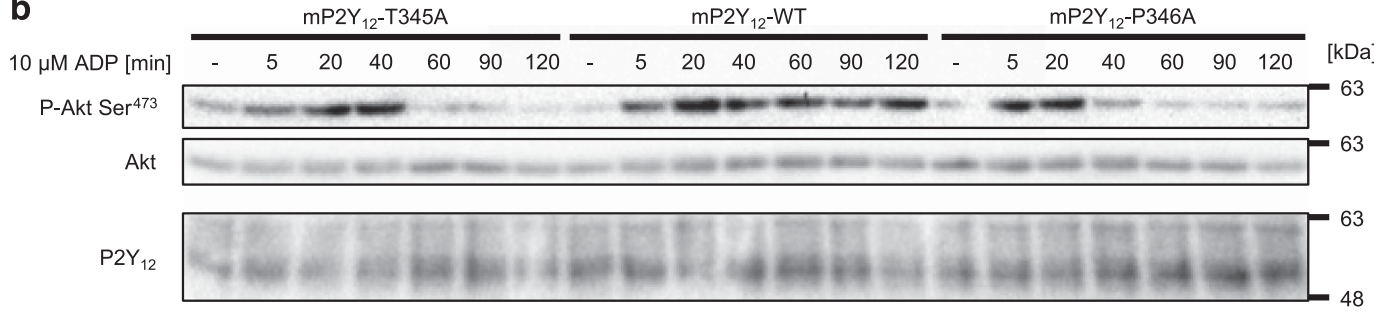

C
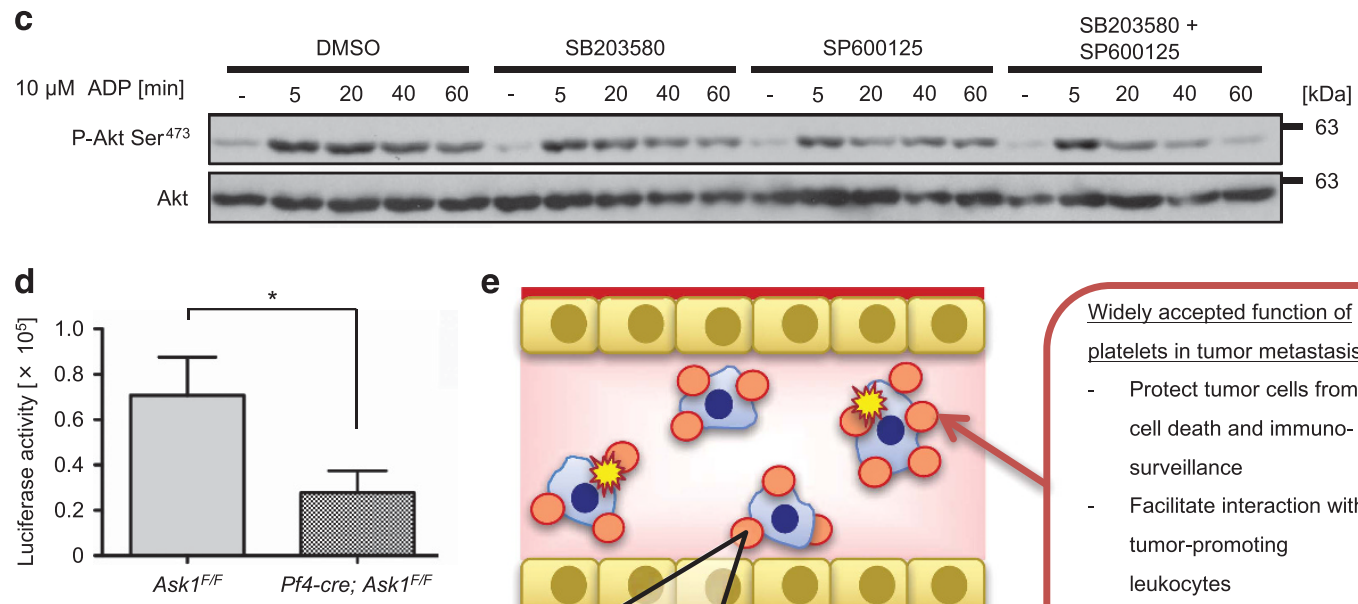

e

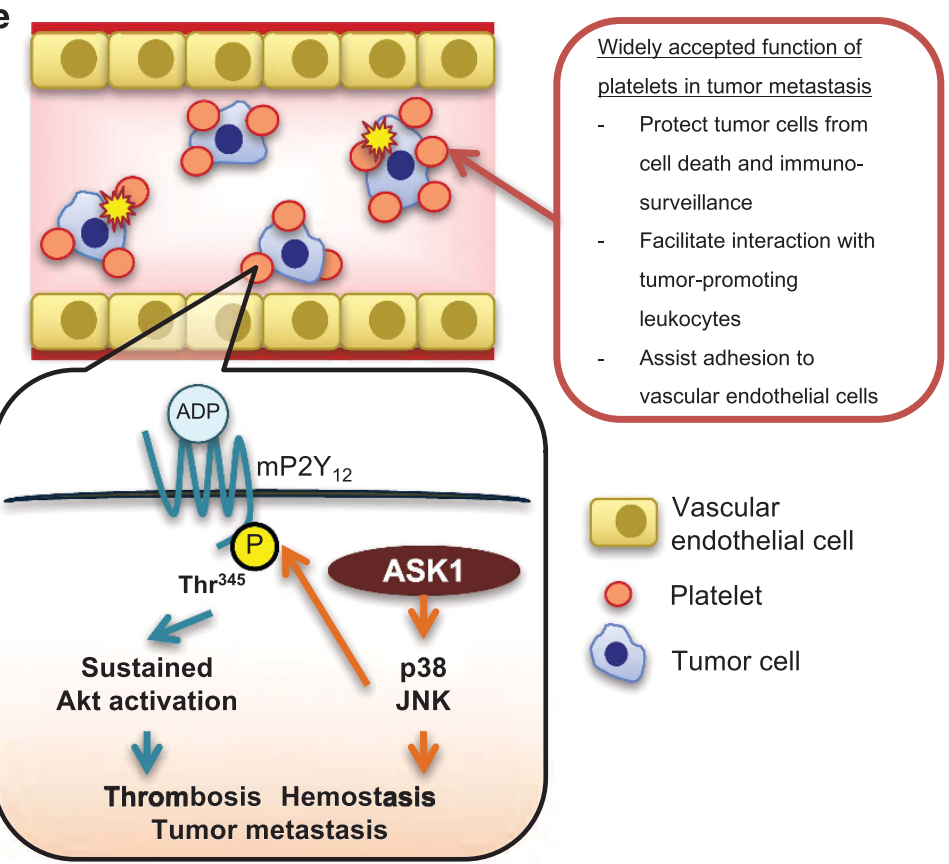

Figure 5 ASK1-JNK/p38 axis regulates sustained Akt activation induced by ADP stimulation and platelet-dependent tumor metastasis. (a) Akt phosphorylation by ADP stimulation in $\mathrm{CHO}$ cells exogenously expressing control lacZ or mouse $\mathrm{P}_{2} \mathrm{Y}_{12}\left(\mathrm{mP}_{2 \mathrm{Y}}{ }_{12}\right.$ )-WT. (b) The phosphorylation-defective (T345A) and recycling-defective (P346A) mutants of $\mathrm{mP}_{2} \mathrm{Y}_{12}$ lost sustained Akt signaling by ADP stimulation in $\mathrm{CHO}$ cells. (c) JNK and $\mathrm{p} 38$ inhibition synergistically suppressed sustained Akt signaling induced by ADP stimulation in $\mathrm{CHO}$ cells exogenously expressing mP2Y ${ }_{12}$-WT. (d) Luciferase activity of lung lysates 14 days after i.v. injection of B16F10-luc-G5 cells (Ask $1^{F / F}$ mice: $n=11, P f 4-c r e ; A s k 1^{F / F}$ mice: $n=10$ ). The data are presented as the mean \pm s.e.m. ${ }^{*} P<0.05$. Unpaired Student's $t$-tests (d). (e) ASK1-JNK/p38 axis in platelets facilitates ADP-induced Akt activity by phosphorylation of $\mathrm{mP}_{2} \mathrm{Y}_{12}$ at Thr345 and platelet-dependent tumor metastasis 
A previous study identified a patient with a substitution from Pro to Ala in the corresponding TP site (P341A) of human $\mathrm{P}_{2} \mathrm{Y}_{12}$ and suggested that this mutation attenuates receptor internalization and resensitization, resulting in bleeding phenotype. $^{29}$ Defects in resensitization of GPCRs impair sustained downstream signaling in general. ${ }^{30}$ Consistently, Akt activity in $\mathrm{CHO}$ cells exogenously expressing $\mathrm{mP}_{2} \mathrm{Y}_{12}{ }^{-}$ P346A mutant (P341A in human) was clearly attenuated from 40 to 60 min after ADP stimulation (Figure $5 \mathrm{~b}$ ), which is similar to -T345A mutant. Moreover, pretreatment with JNK and p38 inhibitors additively reduced ADP-dependent Akt activity from 40 to $60 \mathrm{~min}$ with little effect at $5 \mathrm{~min}$ after stimulation (Figure $5 \mathrm{c}$ ), consistent with the result of $\mathrm{mP}_{2 \mathrm{Y}_{12}}$ T345A mutant. These results suggest that JNK and p38 are responsible kinases, which phosphorylate $\mathrm{mP}_{2} \mathrm{Y}_{12}$ at Thr345 and enable sustained Akt activation through $\mathrm{mP}_{2} \mathrm{Y}_{12}$. Collectively, our data suggest that platelet-intrinsic ASK1-JNK/p38 axis maintains stable hemostasis and proper ADP signaling in platelets through phosphorylation of $\mathrm{mP}_{2} \mathrm{Y}_{12}$ at Thr345.

Ask1 deficiency in platelets attenuates tumor lung metastasis. Hemostasis and ADP-dependent platelet aggregation were attenuated in $P 2 y_{12}{ }^{-I-}$ mice ${ }^{31}$ and conversely enhanced in transgenic mice expressing the constitutively active form of $P 2 y_{12}\left(c P 2 y_{12}-T g\right.$ mice $),{ }^{32}$ indicative of essential roles of $\mathrm{P}_{2} \mathrm{Y}_{12}$ in platelet functions. Moreover, deletion of $P 2 y_{12}$ in mice ${ }^{11}$ or treatment of $P 2 Y_{12}$-specific inhibitors such as clopidogrel and ticagrelor to mice ${ }^{33}$ attenuated tumor metastatic burden, suggesting the pivotal roles of $\mathrm{P}_{2} \mathrm{Y}_{12}$ in tumor metastasis. Thus, we examined whether Ask1 deficiency solely in platelets attenuates tumor lung metastasis, although ASK1 contributes to metastasis in both bone marrow-derived cells and recipient cells (Figure 2a). Luciferase activity at 14 days after i.v. injection of B16F10-luc-G5 cells was significantly reduced in lung lysates from Pf4-cre; Ask $1^{F / F}$ compared with Ask $1^{F / F}$ mice (Figure $5 \mathrm{~d}$ ). Hence, Ask1 deficiency in platelets attenuates platelet functions, leading to unstable hemostasis and reduced tumor metastatic burden. Collectively, our data suggest that plateletintrinsic ASK1-JNK/p38 axis may validate proper ADP signaling in platelets through phosphorylation of $\mathrm{mP}_{2} \mathrm{Y}_{12}$ at Thr345, which enhances thrombosis/hemostasis and hematogenous tumor metastasis (Figure 5e).

\section{Discussion}

This study elucidated for the first time the regulatory mechanism by which an MAP3K, the most upstream components of the MAPK pathway, contributes to tumor lung metastasis and platelet functions in vitro and in vivo. A part of the present study on thrombus formation using the conventional $A s k 1^{-1-}$ mice is consistent with a recent report from other laboratory. ${ }^{15}$ Our study further elucidated the regulatory mechanism of tumor metastasis by ASK1 in platelets utilizing conventional and platelet-specific Ask1-deficient mice. Furthermore, we revealed that not only $\mathrm{JNK} / \mathrm{p} 38$ but also Akt activity was strongly reduced in Ask1-deficient platelets (Figures $3 e$ and $f$ ) and that $P 2 Y_{12}$ is a direct substrate downstream of
ASK1-JNK/p38 axis, which regulates sustained Akt activity (Figures $5 b$ and $\mathrm{c}$ ).

In this study, however, we cannot exclude other mechanisms than phosphorylation of $\mathrm{P}_{2} \mathrm{Y}_{12}$, which are responsible for attenuation of tumor metastasis by platelet-intrinsic Ask1 deficiency. It was recently reported that ASK1 contributes to granule secretion and production of thromboxane $A_{2}$ from platelets under various conditions including ADP stimulation. ${ }^{15}$ Moreover, a variety of factors secreted from granules facilitate tumor metastasis via platelet activation and aggregation, and interaction between platelets and tumor cells. ${ }^{9}$ Therefore, our proposed regulatory mechanism of $\mathrm{P}_{2} \mathrm{Y}_{12^{-}}$ mediated ADP signaling by ASK1 might be independent or upstream as well as downstream of secreted factors from platelets.

As mentioned previously, ADP activates two purinergic GPCRs, $\mathrm{P}_{2} \mathrm{Y}_{1}$ and $\mathrm{P}_{2} \mathrm{Y}_{12}$, to initiate platelet aggregation. Naik et al. also demonstrated that the extent of intracellular calcium influx within platelets stimulated with ADP is comparable between Wt and $A s k 1^{-1-}$ mice. Considering that $\mathrm{P}_{2} \mathrm{Y}_{1}$ is responsible for intracellular calcium influx under ADP stimulation, ${ }^{26}$ it seems unlikely that ASK1 modulates ADP signaling in platelets and thereby platelet-dependent tumor metastasis through $\mathrm{P}_{2} \mathrm{Y}_{1}$.

The importance of N-type glycosylation of $\mathrm{P}_{2} \mathrm{Y}_{12}$ is reported for its signaling; ${ }^{34}$ however, the impact of phosphorylation of $\mathrm{P}_{2} \mathrm{Y}_{12}$ on its function and subsequent hemostasis and tumor metastasis has been largely unknown. We newly identified Thr345 of $\mathrm{mP2Y}_{12}$, which is subject to phosphorylation by the ASK1-JNK/p38 axis, and revealed that this phosphorylation is important for ADP signaling. Although lines of evidence suggest that GPCRs modulate MAPK signaling as downstream effectors, ${ }^{30}$ the present study is the first to report that the JNK/p38 pathway directly phosphorylates GPCR and thereby regulate its function. As mentioned, engagement of ADP to $\mathrm{P}_{2} \mathrm{Y}_{12}$ leads to inhibition of $A C$ as well as activation of the PI3K-Akt pathway. $G a_{i}$ and $G \beta / \gamma$ coupled to $\mathrm{P}_{2} \mathrm{Y}_{12}$ are responsible for the former and the latter signaling, respectively. ${ }^{26}$ Our data suggested that ASK1-mediated phosphorylation of $\mathrm{P}_{2} \mathrm{Y}_{12}$ affects $\mathrm{PI3K}-\mathrm{Akt}$ pathway; however, it is also considerable not only $\mathrm{G} \beta / \gamma$ - but also $\mathrm{G} a_{\mathrm{i}}$-mediated signaling to $\mathrm{AC}$ may be affected by phosphorylation of $P 2 Y_{12}$. Further study is needed to investigate the effects of ASK1 and of phosphorylation at Thr345 of P2Y 12 on the activity of $A C$.

Of note, P341A mutation of human $\mathrm{P}_{2} \mathrm{Y}_{12}$ was found in a patient with bleeding phenotype and suggested to attenuate receptor internalization and resensitization. ${ }^{29}$ In general, defects in resensitization of GPCRs impair sustained downstream signaling. ${ }^{30}$ It is thus plausible that ADP-dependent sustained Akt activity as a downstream of $\mathrm{P}_{2} \mathrm{Y}_{12}$ may be affected in P341A (P346A in mice) mutant. We revealed that sustained activity of Akt was abolished not only in $\mathrm{CHO}$ cells exogenously expressing $\mathrm{mP}_{2} \mathrm{Y}_{12}-\mathrm{P} 346 \mathrm{~A}$ mutant but also in those expressing $\mathrm{mP}_{2} \mathrm{Y}_{12}-\mathrm{T} 345 \mathrm{~A}$ mutant (Figure $5 \mathrm{~b}$ ). Moreover, $\mathrm{CHO}$ cells exogenously expressing $\mathrm{mP}_{2} \mathrm{Y}_{12}-\mathrm{WT}$ treated with inhibitors of JNK and/or p38 also had defects in sustained activity of Akt (Figure 5c). These data suggest that defects in phosphorylation of $\mathrm{mP}_{2} \mathrm{Y}_{12}$ at Thr345 by ASK1-JNK/p38 axis may attenuate downstream signaling via recycling and/or 
resensitization of $\mathrm{P}_{2} \mathrm{Y}_{12}$ in the similar manner as $\mathrm{P} 346 \mathrm{~A}$ mutant. Previous study suggested that activated $P 2 Y_{12}$ by ADP is subject to phosphorylation by GPCR kinase (GRK) 2 and GRK6, resulting in desensitization; ${ }^{35}$ however, the phosphorylation sites of $\mathrm{P}_{2} \mathrm{Y}_{12}$ by these kinases and the precise mechanism of the phosphorylation have not been identified. It is possible that GRKs also regulate the phosphorylation of $\mathrm{mP}_{2} \mathrm{Y}_{12}$ at Thr345 as ASK1-JNK/p38 axis. Thus, further study is needed to investigate how and whether ASK1-JNK/p38 axis and GRKs cooperate to regulate $\mathrm{P}^{2} \mathrm{Y}_{12}$ function.

We have revealed that Ask1 deficiency attenuates tumor metastasis, resulting in the drastic extension of the lifespan. Importantly, ASK1 not only in bone marrow-derived cells but also in recipient cells in the setting of bone marrow chimeric mice is required for tumor metastasis (Figure $2 a$ ). These data suggest that ASK1 not only in platelets but in other cell types, such as fibroblasts and/or endothelial cells, may also promote tumor metastasis. Further study is needed to reveal the function of ASK1 in those cell types in the context of tumor metastasis. Moreover, not only the multifaceted functions of ASK1 in multiple cell types but also the quantitative fluctuation of ASK1 may be involved in the progression of tumor metastasis. It is possible, for example, that upregulated ASK1 in platelets in the presence of incipient tumor metastasis might further facilitate $\mathrm{P}_{2} \mathrm{Y}_{12}$ and platelet functions to aggravate tumor metastasis.

In conclusion, our study provides a molecular insight into regulation of tumor metastasis by platelet-intrinsic ASK1 and may implicate a therapeutic potential of ASK1 against tumor metastasis.

\begin{abstract}
Materials/Subjects and Methods
Mice. The generation of $A s k 1^{-1-}$ mice has been described previously. ${ }^{6}$ Mice homozygous for the Ask1 floxed allele $\left(A s k{ }^{F / F}\right)$ on a $\mathrm{C} 57 \mathrm{BL} / 6$ background were generated as previously described. ${ }^{36,37}$ Pf4-cre mice were purchased at the Jackson Laboratory (Sacramento, CA, USA). Lysm-cre mice were obtained from RIKEN (Tsukuba, Japan). The mice were housed in a specific pathogen-free facility and were used for experiments at 8- to 16-week-old. Age-matched female mice were used for all experiments. The experimental protocol was approved by the animal ethics committee of The University of Tokyo (Tokyo, Japan).
\end{abstract}

Bone marrow chimeras. Chimeras were generated by reconstituting irradiated (10 Gy of $\gamma$-radiation) 8-week-old $W t$ and Ask $1^{-1-}$ mice with bone marrow cells $\left(1.7 \times 10^{7}\right.$ cells, i.v.) from sex-matched Wt or $A s k 1^{-1-}$ donor mice. Eight weeks later, tumor implantation was carried out as described below. Lung dissection was performed 7 days after tumor cell injection.

Cell culture. Luciferase-expressing Lewis lung carcinoma 3LL (3LL-Luc2) cell line was kindly provided by Dr. Yoshihiro Hayakawa (University of Toyama). Luciferase-expressing melanoma B16F10-luc-G5 cells (Xenogen Corp., Alameda, CA, USA) were maintained in DMEM-high glucose medium (Sigma, St. Louis, MO, USA) supplemented with 100 units/ml penicillin G, 10\% fetal bovine serum (FBS) and $0.25 \mathrm{mg} / \mathrm{ml}$ zeocin. 3 LL-Luc2 cells were maintained in RPMI-1640 medium (Sigma) supplemented with 100 units $/ \mathrm{ml}$ penicillin $\mathrm{G}$ and $10 \%$ FBS. Chinese Hamster Ovary (CHO) cells were maintained in Ham's F-12 medium (Wako Chemicals, Osaka, Japan) supplemented with 100 units $/ \mathrm{ml}$ penicillin $\mathrm{G}$ and $10 \%$ FBS. Cells were cultured in a $5 \% \mathrm{CO}_{2}$ atmosphere at $37^{\circ} \mathrm{C}$. The absence of mycoplasma was confirmed.

Antibodies and reagents. The polyclonal antibody to phospho-ASK1 (pT845) was described previously, ${ }^{38}$ which was used as P-ASK antibody. The antibody to ASK1 (EP553Y) was purchased from Abcam (Cambridge, UK) and the antibody to $\mathrm{P}_{2} \mathrm{Y}_{12}$ (APR-012) was purchased from Alomone Labs (Jerusalem,
Israel). Phospho-specific antibodies to JNK (P-JNK: $\operatorname{Thr}^{183} / \mathrm{Tyr}^{185}$ ), p38 MAPK (P-p38: Thr ${ }^{180} / \mathrm{Tyr}^{182}$ ), Akt (P-Akt Ser ${ }^{473}$ and P-Akt Thr ${ }^{308}$ ) and the antibody to p38 (p38 L53F8) and Akt (pan) (11E7) were purchased from Cell Signaling (Danvers, MA, USA). The antibody to JNK (JNK-FL) and Actin (AC-40) were purchased from Santa Cruz (Dallas, TX, USA). A rabbit polyclonal antibody specific for phospho$\mathrm{P} \mathrm{Y}_{12}\left(\mathrm{P}-\mathrm{P} 2 \mathrm{Y}_{12} \mathrm{Thr}^{345}\right)$ was raised against the phosphopeptide GEPSEE(pT)PM of mouse $\mathrm{P}_{2} \mathrm{Y}_{12}$ as described previously. ${ }^{39}$ ADP was purchased from Wako. p38 inhibitor SB203580 and JNK inhibitor SP600125 were purchased from Merck Millipore (Billerica, MA, USA). Cells were pretreated with SB203580 and/

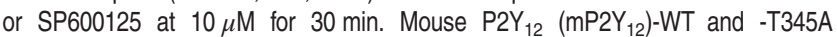
constructs were generated by PCR of mouse blood cDNA template and cloned into pAd/CMV/V5 to generate adenoviruses encoding the above-mentioned constructs or control lacZ according to the manufacturer's instructions (Invitrogen, Carlsbad, CA, USA).

Tumor transplantation. For experimental lung metastasis model, following number of tumor cells were injected i.v.: 1,2 or $6 \times 10^{5}$ cells/mouse for 3LL-Luc2 cells and $4 \times 10^{5}$ cells/mouse for B16F10-luc-G5 cells. Fourteen days or at indicated time points (Figure 1f) after i.v. injection, lungs were dissected and analyzed by macroscopic observation and/or by luciferase activity assay. Alternatively, we injected $2 \times 10^{5}$ 3LL-Luc2 cells subcutaneously into the dorsal skin, while $1 \times 10^{3}$ 3LL-Luc2 cells with BD Matrigel Matrix Growth Factor Reduced (BD Biosciences, Franklin Lakes, NJ, USA) were orthotopically injected into the lung. Subcutaneous tumor volumes were measured with calipers and calculated using following formula: tumor volume $=\left(\right.$ major axis $\times$ minor axis $\left.{ }^{2}\right) / 2$.

Luciferase activity assay. Mouse lungs were homogenized in Luciferase Culture Lysis $5 \times$ Reagent diluted with distilled water (Promega, Madison, WI, USA). The lysates were cleared by centrifugation and analyzed using the Luciferase Assay System (Promega).

In vivo bioluminescence imaging. Mice were epilated, anesthetized with avertin and administered D-luciferin potassium (Wako Chemicals) intraperitoneally to monitor luciferase activity in vivo with NightOWL II LB983 (Berthold Technologies, Bad Wildbad, Germany). The luciferase activity from the ROI was measured in units of photons per second.

Tail bleeding assay. Mice were anesthetized with pentobarbital $(50 \mathrm{mg} / \mathrm{kg}$, intraperitoneally) and placed in a cloth holder warmed to $37^{\circ} \mathrm{C}$. The mouse tail was transected $5 \mathrm{~mm}$ from the tip, immersed in PBS at $37^{\circ} \mathrm{C}$ and the bleeding time was determined when the bleeding stopped for more than $30 \mathrm{~s}$. Tail bleeding assay was ceased at $600 \mathrm{~s}$ if the bleeding did not stop.

$\mathrm{FeCl}_{3}$-induced thrombosis model. Mice were anesthetized and the right femoral artery was exposed and $1 \mathrm{~mm}^{2}$ filter paper immersed in $10 \% \mathrm{FeCl}_{3}$ was applied onto it. The occlusion time was determined if the flow fell below $10 \mathrm{ml} / \mathrm{min}$ per $100 \mathrm{~g}$ weight for $1 \mathrm{~min}$.

Measurement of hematological parameters. Mouse blood was collected from the tips of mouse tail and diluted with $25 \mathrm{~mm}$ EDTA/PBS. Hematological parameters were analyzed by XE-2100 (Sysmex, Kobe, Japan).

Isolation of platelets for platelet aggregation. Whole blood was collected into tubes with citrate anticoagulant from anesthetized mice by inferior vena cava puncture with a 23-gauge needle. Supernatants were collected after centrifuging blood ( $100 \times g$ for 10 min twice) for preparation of platelet-rich plasma (PRP). Platelets were precipitated by centrifugation of PRP (2300 r.p.m. for $10 \mathrm{~min}$ ) with $10 \mathrm{nM}$ prostacyclin (Cayman Chemical, Ann Arbor, MI, USA). Precipitated platelets were suspended in Calcium-Free Tyrode buffer (CFT) to adjust platelet population (platelet suspension). Aggregation of platelet suspension was analyzed with MCM HEMA TRACER 712 (MC MEDICAL, Tokyo, Japan) for $10 \mathrm{~min}$. Platelet aggregation was induced with collagen ( $1 \mu \mathrm{g} / \mu \mathrm{l}$; Takeda, Osaka, Japan), PAR-4 (50 $\mu \mathrm{M}$; Sigma), rhodocytin ( $1 \mathrm{nM}$, purified as previously described), ${ }^{40} \mathrm{ADP}(10 \mu \mathrm{M}$; MC Medical) and thrombin (0.025 U/ml; Haematologic Technologies, Essex Junction, VT, USA).

Surface expression of platelet receptors by flow cytometry. Samples of PRP were incubated with the following antibodies and analyzed by FACS Accuri C6 (BD Biosciences): FITC-labeled anti-mouse CD41 (clone MWReg30; BD Biosciences), FITC-labeled anti-CD61 (clone Luc.H11; Haematologic Technologies), 
FITC-labeled anti-mouse GPVI (clone JAQ-1; Emfret Analytics), PE-labeled antimouse CD49 (clone HM $\alpha 2$; BD Biosciences), PE-labeled anti-mouse CD42b (clone Xia.G5; Emfret Analytics, Eibelstadt, Germany) and Alexa Fluor 488-labeled antimouse CLEC-2 (clone 2A2B10; Cell Signaling, labeled with Alexa Fluor 488 antibody labeling kit (Life Technologies, Carlsbad, CA, USA)).

Preparation of tissue extracts. Mouse lungs were isolated and lysed with Cell Culture Lysis Buffer (Promega) using an electron homogenizer. Collected supernatants by centrifugation were mixed with the equal amount of $2 \times$ loading buffer (4\% SDS, $100 \mathrm{~mm}$ Tris-HCl pH 8.8, 10\% bromophenol blue, 36\% glycerol and $10 \mathrm{~mm}$ dithiothreitol) and subjected to western blot. For preparation of peritoneal macrophages $(\mathrm{pM} \varphi \mathrm{s})$, mice were administered thioglycollate $(3.85 \mathrm{mg} / \mathrm{ml}$, intraperitoneally) to induce peritonitis and $\mathrm{pM} \varphi s$ were collected 4 days later and cultured in RPMl-1640 medium (Sigma) supplemented with 100 units/ml penicillin G and $10 \%$ FBS. To detect ASK1 clearly and to magnify the difference of ASK1 protein expression, $\mathrm{pM} \varphi$ were treated with $1 \mu \mathrm{g} / \mathrm{ml}$ LPS for $24 \mathrm{~h}$ and were lysed with IP lysis buffer ( $150 \mathrm{~mm} \mathrm{NaCl}, 50 \mathrm{~mm}$ Tris-HCl, $10 \mathrm{~mm}$ EGTA, 1\% Triton X-100, 0.5\% sodium deoxycholate, $1 \mathrm{~mm}$ phenylmethylsulfonyl fluoride and $1 \mu \mathrm{M}$ leupeptin). The lysates were cleared by centrifugation, mixed with the equal amount of $2 \times$ loading buffer and subjected to western blot. As for isolation of platelets for western blot, mouse blood was collected into tubes with citrate anticoagulant from anesthetized mice by inferior vena cava puncture with a 24-gauge needle. After centrifuging blood (100 $\times g$ for 10, 9 and $8 \mathrm{~min}$ ), the collected supernatants were again centrifuged at 1000 r.p.m. for $10 \mathrm{~min}$ to collect supernatants. Platelets were precipitated by centrifugation of the collected supernatants (3000 r.p.m. for $10 \mathrm{~min}$ ) with $10 \mathrm{nM}$ prostacyclin. Precipitated platelets were suspended in CFT to adjust platelet number. Suspended platelets were lysed by adding the equal amount of $2 \times$ loading buffer. For $\lambda$ PPase treatment, suspended platelets were again centrifuged at 3000 r.p.m. for $10 \mathrm{~min}$ with $10 \mathrm{nM}$ prostacyclin followed by lysis with RIPA buffer (50 mu Tris-HCl pH 8.0, $150 \mathrm{~mm} \mathrm{NaCl}, 1 \%$ NP-40, 0.5\% DOC, 0.1\% SDS, $1 \mathrm{~mm}$ PMSF, $5 \mu \mathrm{g} / \mathrm{ml}$ leupeptin, $8 \mathrm{~mm} \mathrm{NaF}, 12 \mathrm{~mm}$ beta-glycerophosphate, $1 \mathrm{~mm} \mathrm{Na}_{3} \mathrm{VO}_{4}$, $1.2 \mathrm{mM} \mathrm{Na}_{2} \mathrm{MoO}_{4}, 5 \mu \mathrm{m}$ Cantharidin and $2 \mathrm{~mm}$ Imidazole). The lysates were cleared by centrifugation and subjected to dephosphorylation by $\lambda$ PPase (BioLabs, Ipswich, MA, USA) according to the manufacturer's instructions, mixed with the equal amount of $2 \times$ loading buffer and subjected to western blot.

Preparation of cell lysates. $\mathrm{CHO}$ cells were infected with adenoviruses encoding mouse $\mathrm{P} 2 \mathrm{Y}_{12}-\mathrm{WT}$, -T345A,-P346A or control lacZ constructs and the medium was changed $48 \mathrm{~h}$ after infection. After ADP stimulation if indicated, cells were lysed with RIPA lysis buffer containing Phosphatase Inhibitor Cocktail $(320 \mu \mathrm{M}$ $\mathrm{NaF}, 480 \mu \mathrm{m}$ beta-glycerophosphate, $40 \mu \mathrm{M} \mathrm{Na}_{3} \mathrm{VO}_{4}, 48 \mu \mathrm{M} \mathrm{Na}_{2} \mathrm{MoO}_{4}, 200 \mathrm{nM}$ Cantharidin, $80 \mu \mathrm{m}$ Imidazole). The lysates were cleared by centrifugation, mixed with the equal amount of $2 \times$ loading buffer and subjected to western blot.

Western blot. Cell lysates and tissue extracts were resolved on SDS-PAGE and electroblotted onto polyvinylidene difluoride membranes. After blocking with $5 \%$ skim milk in TBS-T ( $50 \mathrm{~mm}$ Tris- $\mathrm{HCl}, 150 \mathrm{~mm} \mathrm{NaCl}$ and $0.05 \%$ Tween 20, pH 8.0), the membranes were probed with appropriate antibodies. The antibody-antigen complexes were detected using the ECL system (GE Healthcare, Little Chalfont, UK) as described previously. ${ }^{38}$

Statistical analysis. All statistical analyses were carried out with GraphPad Prism software. Unpaired Student's $t$-tests, Mann-Whitney U-test, one-way ANOVA followed by Ryan's method, or Gehan-Breslow-Wilcoxon test were used.

\section{Conflict of Interest}

The authors declare no conflict of interest.

Acknowledgements. We thank Dr. Tetsuro Watabe for advice and Dr. Ayako Nishihara for technical assistance. We thank all the members of laboratory of Cell Signaling. This work was supported by Grant-in-Aid for Scientific Research on Innovative Areas and Grants-in-Aid for Scientific Research (KAKENHI) from the Japanese Society for the Promotion of Sciences (JSPS) and the Japanese Ministry of Education, Culture, Sports, Science and Technology (MEXT).

1. Chaffer $C L$, Weinberg RA. A perspective on cancer cell metastasis. Science 2011; 331: $1559-1564$.
2. Widmann C, Gibson S, Jarpe MB, Johnson GL. Mitogen-activated protein kinase: conservation of a three-kinase module from yeast to human. Physiol Rev 1999; 79: 143-180.

3. Murakami S, Noguchi T, Takeda K, Ichijo H. Stress signaling in cancer. Cancer Sci 2007; 98: $1521-1527$.

4. Wagner EF, Nebreda ÁR. Signal integration by JNK and p38 MAPK pathways in cancer development. Nat Rev Cancer 2009; 9: 537-549.

5. Ichijo H, Nishida E, Irie K, Dijke P, Saitoh M, Moriguchi T et al. Induction of apoptosis by ASK1, a mammalian MAPKKK that activates SAPK/JNK and p38 signaling pathways. Science 1997; 275: 90-94.

6. Tobiume K, Matsuzawa A, Takahashi T, Nishitoh H, Morita K, Takeda K et al. ASK1 is required for sustained activations of JNK/p38 MAP kinases and apoptosis. EMBO Rep 2001; 2: 222-228.

7. Iriyama $\mathrm{T}$, Takeda $\mathrm{K}$, Nakamura $\mathrm{H}$, Morimoto $\mathrm{Y}$, Kuroiwa T, Mizukami $\mathrm{J}$ et al. ASK1 and ASK2 differentially regulate the counteracting roles of apoptosis and inflammation in tumorigenesis. EMBO J 2009; 28: 843-853.

8. Kamiyama M, Naguro I, Ichijo H. In vivo gene manipulation reveals the impact of stress-responsive MAPK pathways on tumor progression. Cancer Sci 2015; 106: 785-796.

9. Gay LJ, Felding-Habermann B. Contribution of platelets to tumour metastasis. Nat Rev Cancer 2011; 11: 123-134

10. Kim YJ, Borsig L, Varki NM, Varki A. P-Selectin deficiency attenuates tumor growth and metastasis. Proc Natl Acad Sci 1998; 95: 9325-9330.

11. Wang $Y$, Sun $Y$, Li D, Zhang L, Wang K, Zuo $Y$ et al. Platelet $P 2 Y 12$ is involved in murine pulmonary metastasis. PLOS ONE 2013; 8: e80780.

12. Francia G, Cruz-Munoz W, Man S, Xu P, Kerbel RS. Mouse models of advanced spontaneous metastasis for experimental therapeutics. Nat Rev Cancer 2011; 11: 135-141.

13. Quail DF, Joyce JA. Microenvironmental regulation of tumor progression and metastasis. Nat Med 2013; 19: 1423-1437.

14. Clemens RA, Lenox LE, Kambayashi T, Bezman N, Maltzman JS, Nicols KE et al. Loss of SLP-76 expression within myeloid cells confers resistance to neutrophilmediated tissue damage while maintaining effective bacterial killing. J Immunol 2007; 178: 4606-4614.

15. Naik MU, Patel $P$, Derstine $R$, Turaga $R$, Chen $X$, Golla $K$ et al. Ask1 regulates platelet granule secretion, thromboxane A2 generation, and thrombus formation in mice. Blood 2017; 129: 1197-1209.

16. Tiedt R, Schomber T, Hao-Shen H, Skoda RC. Pf4-Cre transgenic mice allow the generation of lineage-restricted gene knockouts for studying megakaryocyte and platelet function in vivo. Blood 2007; 109: 1503-1506.

17. Kramer RM, Roberts EF, Strifler BA, Johnstone EM. Thrombin induces activation of p38 MAP kinase in human platelets. J Biol Chem 1995; 270: 27395-27398.

18. Bugaud F, Nadal-Wollbold F, Lévy-Toledano S, Rosa J-P, Bryckaert M. Regulation of c-Jun- $\mathrm{NH} 2$ terminal kinase and extracellular-signal regulated kinase in human platelets. Blood 1999; 94: 3800-3805.

19. Woulfe DS. Akt signaling in platelets and thrombosis. Expert Rev Hematol 2010; 3 : 81-91.

20. Kim AH, Khursigara G, Sun X, Franke TF, Chao MV. Akt phosphorylates and negatively regulates apoptosis signal-regulating kinase 1. Mol Cell Biol 2001; 21: 893-901.

21. Subramanyam M, Takahashi N, Hasegawa Y, Mohri T, Okada Y. Inhibition of protein kinase Akt1 by apoptosis signal-regulating kinase-1 (ASK1) is involved in apoptotic inhibition of regulatory volume increase. J Biol Chem 2010; 285: 6109-6117.

22. Nieswandt B, Watson SP. Platelet-collagen interaction: is GPVI the central receptor? Blood 2003; 102: 449-461.

23. Pollitt AY, Grygielska B, Leblond B, Désiré L, Eble JA, Watson SP. Phosphorylation of CLEC-2 is dependent on lipid rafts, actin polymerization, secondary mediators, and Rac. Blood 2010; 115: 2938-2946.

24. Suzuki-Inoue K, Inoue O, Ozaki Y. Novel platelet activation receptor CLEC-2: from discovery to prospects. J Thromb Haemost 2011; 9: 44-55.

25. Lova P, Campus F, Lombardi R, Cattaneo M, Sinigaglia F, Balduini $C$ et al. Contribution of protease-activated receptors 1 and 4 and glycoprotein $\mathrm{Ib}-\mathrm{IX}-\mathrm{V}$ in the Gi-independent activation of platelet Rap1B by thrombin. J Biol Chem 2004; 279: 25299-25306.

26. Dorsam RT, Kunapuli SP. Central role of the P2Y ${ }_{12}$ receptor in platelet activation. J Clin Invest 2004; 113: 340-345

27. Kim S, Jin J, Kunapuli SP. Akt activation in platelets depends on Gi signaling pathways J Biol Chem 2004; 279: 4186-4195.

28. Cattaneo $M$. The platelet $P 2 Y_{12}$ receptor for adenosine diphosphate: congenital and druginduced defects. Blood 2011; 117: 2102-2112.

29. Nisar S, Daly ME, Federici AB, Artoni A, Mumford AD, Watson SP et al. An intact PDZ motif is essential for correct $\mathrm{P}_{2} \mathrm{Y}_{12}$ purinoceptor traffic in human platelets. Blood 2011; 118: $5641-5651$.

30. Ritter SL, Hall RA. Fine-tuning of GPCR activity by receptor-interacting proteins. Nat Rev Mol Cell Biol 2009; 10: 819-830.

31. André $P$, Delaney $S M$, LaRocca $T$, Vincent $D$, DeGuzman $F$, Jurek $M$ et al. $P 2 Y_{12}$ regulates platelet adhesion/activation, thrombus growth, and thrombus stability in injured arteries. $J$ Clin Invest 2003; 112: 398-406.

32. Zhang Y, Ye J, Hu L, Zhang S, Zhang SH, Li Y et al. Increased platelet activation and

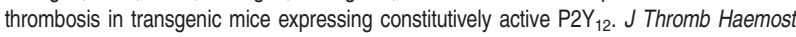
2012; 10: 2149-2157. 
33. Gebremeskel S, LeVatte T, Liwski RS, Johnston B, Bezuhly M. The reversible P2Y12 inhibitor ticagrelor inhibits metastasis and improves survival in mouse models of cancer. Int J Cancer 2015; 136: 234-240.

34. Zhong $X$, Kriz R, Seehra J, Kumar R. N-linked glycosylation of platelet $P_{2} Y_{12} A D P$ receptor is essential for signal transduction but not for ligand binding or cell surface expression. FEBS Lett 2004; 562: 111-117.

35. Hardy AR, Conley PB, Luo J, Benovic JL, Poole AW, Mundell SJ. P2Y ${ }_{1}$ and P2Y ${ }_{12}$ receptors for ADP desensitize by distinct kinase-dependent mechanisms. Blood 2005; 105: 3552-3560.

36. Hattori K, Naguro I, Okabe K, Funatsu T, Furutani S, Takeda K et al. ASK1 signalling regulates brown and beige adipocyte function. Nat Commun 2016; 7: 11158.
37. Kanki $\mathrm{H}$, Suzuki $\mathrm{H}$, Itohara S. High-efficiency CAG-FLPe Deleter mice in C57BL/6J background. Exp Anim 2006; 55: 137-141.

38. Takeda K, Shimozono R, Noguchi T, Umeda T, Morimoto $\mathrm{Y}$, Naguro I et al. Apoptosis signal-regulating kinase (ASK) 2 functions as a mitogen-activated protein kinase kinase kinase in a heteromeric complex with ASK1. J Biol Chem 2007; 282: 7522-7531.

39. Tobiume K, Saitoh M, Ichijo H. Activation of apoptosis signal-regulating kinase 1 by the stressinduced activating phosphorylation of pre-formed oligomer. J Cell Physiol 2002; 191: 95-104.

40. Shin Y, Morita T. Rhodocytin, a functional novel platelet agonist belonging to the heterodimeric C-type Lectin family, induces platelet aggregation independently of glycoprotein Ib. Biochem Biophys Res Commun 1998; 245: 741-745.

Supplementary Information accompanies this paper on Cell Death and Differentiation website (http://www.nature.com/cdd) 